5 Vité, J. P., Hedden, R. L., and Mori, K., Naturwissenschaften, 63, 43 (1976).

6 Vité, J. P., and Pitman, G. B., Proc. XIV Int. Union Forest Res. Org., 24, 683-701 (1967).

Vité, J. P., Gara, R. I., and Von Schiller, H. D., Contrib. Boyce Thompson Inst., $22,461-470$ (1964).

8 Vité, J. P., and Pitman., G. B., Can. Entom., 101, 113-117 (1969).

9 Mori, K., Tetrahedron Lett., 2187 (1975): Tetrnhedron (in the press).

Atkins, M. D., Can. Entom., 98, 285-288 (1966). Wood, D. L., in Control of Insect Behaviour by Natural Products, 301-316
(Academic, New York, 1970).

12 Lanier, G. N., and Burkholder, W. E., in Pheromones, 161-189 (North-Holland, Amsterdam, 1974).

13 Birch, M. C., and Wood, D. L., J. chem. Ecol., 1, 101 113 (1975).

\section{Evidence that blackfly larvae can feed on particles of colloidal size}

Filtration of colloidal particles has not previously been reported for animals living in flowing freshwaters. The observation that blackfly larvae (Diptera : Simuliidae) can filter such particles may alter our understanding of the nutrition of these suspension-feeding animals and also afford new possibilities for the control of the insect in areas where the adult females are vectors of onchocerciasis.

Blackfly larvae are equipped with specialised mouthparts, the cephalic fans, which, when extended into the current, trap suspended particles. At intervals the fans are folded and particles trapped on the fans are removed by the mandibles, passed to the cibarium and, thence, to the foregut. Recorded lengths of ingested particles vary between 0.5 and $300 \mu \mathrm{m}$ with the majority in the range $20-100 \mu \mathrm{m}$ for some Canadian larvae ${ }^{1}$, and from $11.3 \pm 1.8$ to $15.1 \pm 2.0 \mu \mathrm{m}$ for several British species ${ }^{2}$. That larvae can feed exclusively on fine particles has been demonstrated by rearing them to pupation on a diet of Bacillus subtilis (Ehr.) Cohn in distilled water ${ }^{3}$.

In the present investigation an aquarium tank $(13 \times 13 \times$ $17 \mathrm{~cm}$ ) was filled with distilled water and a circulating current created by an air pump. A concentrated suspension of polystyrene latex microspheres (Dow Chemicals) of diameter $0.091 \pm 0.0058 \mu \mathrm{m}$ was added to the water to give a suspension of less than $0.02 \%$ by volume. Large larvae (fifth instars and above, mainly of Simulium nitidifrons Edwards) were collected from a stream and placed in the aquarium for $24 \mathrm{~h}$ after which they were removed and killed in formalin.

The larvae were then cut into thick sections $(\sim 1 \mathrm{~mm})$ using a scalpel and the surface of each viewed in a scanning electron microscope. In section, the gut contents were white and granular. When a little of this material was observed by transmission electron microscopy it was seen to consist of dense, three-dimensional aggregates often composed of many hundreds of latex microspheres.

Aggregations of microspheres were rarely observed in samples from the concentrated, or the dilute experimental suspension. Those aggregates which were observed consisted of few microspheres arranged in a single layer and probably resulted from drying the suspension on grids before examination by transmission electron microscopy. It is therefore concluded that the large three-dimensional aggregates found in the gut must form either on the cephalic fan rays, or as the result of 'packing' after the ingestion of single spheres.

It thus seems that blackfly larvae are able to feed on particles as small as $0.091 \mu \mathrm{m}$ in diameter although the details of the feeding mechanism have yet to be fully understood. The use of particulate insecticides of $10 \mu \mathrm{m}$ diameter against blackfly larvae has been demonstrated to be selective ${ }^{4}$. An insecticide preparation of smaller dimension would reduce sedimentation and allow the treatment to be even more selective.

The nutrition of blackfly larvae has not been studied in detail but fine particles, in addition to larger ones, may form an important part of the diet ${ }^{3}$. In 1909 it was suggested that dissolved organic matter was utilised in the nutrition of some aquatic animals", a theory which has subsequently been questioned. In the light of the present findings this theory may well have some basis in the case of blackfly larvae.

I would like to thank Drs A. J. McLachlan, and G. N. Philipson for critical reading of the manuscript. $\mathrm{Mr}$ A. D. M. Dudgeon and Mr R. McD. Hewit provided technical assistance and scanning electron microscope facilities were provided by the University of Newcastle upon Tyne Electron Optical Unit.

Department of Zoology,

R. S. WotTon

University of Newcastle upon Tyne,

Newcastle upon Tyne NEI 7RU, UK

Received November 14, 1975; accepted May 6, 1976.

1 Chance, M. M., Quaest ent., 6, 245-284 (1970).

2 Williams, T. R., Connolly, R. C., Hynes, H. B. N., and Kershaw, w. E., Nature, $189,78(1961)$

Fredeen, F. J. H., Nature, 187, 963 (1960).

Kershaw, W. E.. et al., Trans. R. Soc. trop. Med. Hyg., 62, 35-40 (1968).

ütter, A., Der Ernährung der Wassertiere und der Stoffhaushalt der Gewässer (Fischer, Jena, 1909).

\section{Prochlorophyta as a proposed new division of algae}

UNICELLULAR algae associated with ascidians from tropical Pacific shores have been reported by various biologists ${ }^{1-5}$. They are bright green, generally spherical and about $10-20 \mu \mathrm{m}$ in diameter, and they seem to have no clearly delimited nucleus or plastids. Such cells (identified as Synechocystis didemni), found associated with surfaces of Didemnum colonies on the Pacific coast of Mexico, have been shown by electron microscopy to be prokaryotic ${ }^{6,7}$, which suggests that they are cyanophytes, that is, bluegreen algae. Although all known blue-green algae (other than a few apochlorotic types) contain phycoerythrin, phycocyanin, or both, however, these ascidian symbionts are apple green and contain no detectable bilin pigments. Furthermore, like the eukaryotic algae in the divisions Chlorophyta and Euglenophyta, they contain two chlorophyll components, separable by chromatography and provisionally identifiable as chlorophylls $a$ and $b$ (ref. 8), whereas no cyanophytes are known to contain chlorophyll $b$. The assignment of $S$. didemni to any of the established algal divisions, therefore, presents a major taxonomic problem.

Algal cells found living inside the colonies of other didemnid ascidians at Enewetak Atoll, Marshall Islands, and on Coconut Island, Hawaii, have been recently studied by the same techniques and have proved to be very much like those of $S$. didemni. My colleagues and I (unpublished results) have confirmed in particular that those from Diplosoma virens (from Hawaii) are prokaryotic, contain chlorophylls $a$ and $b$, contain no detectable bilin pigments (even after incubation for one or more days in nitrogenous media) and show no evidence of phycobilisomes on the thylakoids. In the light, in aerobic conditions, they can fix $\mathrm{CO}$ and evolve oxygen. They must therefore be considered as algae (rather than as photosynthetic bacteria, which are normally anaerobic and, when illuminated, fix $\mathrm{CO}_{2}$ without concomitant oxygen evolution). They cannot, however, be logically assigned to the Cyanophyta, the Chlorophyta, the Euglenophyta, or any other existing division of the algae.

In view of the fact that their peculiar combination of characteristics is common to algal symbionts from several different ascidians found in widely separated locations, it now seems appropriate to put such organisms in a new algal division, which I propose to call the Prochlorophyta. Since it will consequently be necessary to remove the type species, S. didemni, from the Cyanophyta, it can no longer be retained in the blue-green algal genus Synechocystis, in 